Article

\title{
Canadian Wetland Inventory using Google Earth Engine: The First Map and Preliminary Results
}

\author{
Meisam Amani ${ }^{1, *} \mathbb{\infty}$, Sahel Mahdavi ${ }^{1}$, Majid Afshar ${ }^{2}$, Brian Brisco ${ }^{3}$, Weimin Huang ${ }^{4}(\mathbb{D}$, \\ Sayyed Mohammad Javad Mirzadeh ${ }^{5,6}{ }^{(}$, Lori White $^{7}$, Sarah Banks ${ }^{7}$, Joshua Montgomery ${ }^{8}$ and \\ Christopher Hopkinson ${ }^{9}$ \\ 1 Wood Environment \& Infrastructure Solutions, St. John's, NL A1B 1H3, Canada; \\ sahel.mahdavi@woodplc.com \\ 2 Department of Computer Science, Memorial University of Newfoundland, St John's, NL A1B 3X5, Canada; \\ mman23@mun.ca \\ 3 The Canada Center for Mapping and Earth Observation, Ottawa, ON K1S 5K2, Canada; \\ brian.brisco@canada.ca \\ 4 Department of Electrical and Computer Engineering, Memorial University of Newfoundland, St John's, NL \\ A1B 3X5, Canada; weimin@mun.ca \\ 5 Shanghai Astronomical Observatory, Chinese Academy of Sciences, Shanghai 200030, China; \\ m.mirzadeh@shao.ac.cn \\ 6 University of Chinese Academy of Sciences, Beijing 100049, China \\ 7 Environment Canada, National Wildlife Research Centre, Ottawa, ON K1A 0H3, Canada; \\ lori.white2@canada.ca (L.W.); sarah.banks@canada.ca (S.B.) \\ 8 Environmental Monitoring and Science Division, Alberta Environment and Parks, Lethbridge, AB T1J 4L1, \\ Canada; joshua.montgomery@gov.ab.ca \\ 9 Department of Geography, University of Lethbridge, Lethbridge, AB T1K 3M4, Canada; \\ c.hopkinson@uleth.ca \\ * Correspondence: meisam.amani@woodplc.com; Tel.: +1-(709)-771-2888
}

Received: 8 March 2019; Accepted: 4 April 2019; Published: 8 April 2019

\begin{abstract}
Although wetlands provide valuable services to humans and the environment and cover a large portion of Canada, there is currently no Canada-wide wetland inventory based on the specifications defined by the Canadian Wetland Classification System (CWCS). The most practical approach for creating the Canadian Wetland Inventory (CWI) is to develop a remote sensing method feasible for large areas with the potential to be updated within certain time intervals to monitor dynamic wetland landscapes. Thus, this study aimed to create the first Canada-wide wetland inventory using Landsat- 8 imagery and innovative image processing techniques available within Google Earth Engine (GEE). For this purpose, a large amount of field samples and approximately 30,000 Landsat-8 surface reflectance images were initially processed using several advanced algorithms within GEE. Then, the random forest (RF) algorithm was applied to classify the entire country. The final step was an original CWI map considering the five wetland classes defined by the CWCS (i.e., bog, fen, marsh, swamp, and shallow water) and providing updated and comprehensive information regarding the location and spatial extent of wetlands in Canada. The map had reasonable accuracy in terms of both visual and statistical analyses considering the large area of country that was classified $\left(9.985\right.$ million $\left.\mathrm{km}^{2}\right)$. The overall classification accuracy and the average producer and user accuracies for wetland classes exclusively were $71 \%, 66 \%$, and $63 \%$, respectively. Additionally, based on the final classification map, it was estimated that $36 \%$ of Canada is covered by wetlands.
\end{abstract}

Keywords: Canadian Wetland Inventory; Google Earth Engine; Landsat; remote sensing 


\section{Introduction}

Wetlands provide many ecosystem services to the environment, including water purification, protection from natural hazards, soil and water conservation, and shoreline protection [1]. These benefits result from the natural hydrological and biogeochemical processes that occur within wetlands [2]. Hydraulically, wetlands are capable of significant water storage [3] and can serve as a form of natural flood control [1]. Biogeochemically, wetlands can transform and retain several environmental toxins. For example, reactive nitrogen, which has adverse impacts on climate, water ecosystems, and human health, can be managed by wetlands through the transformation of nitrogen via microbial denitrification [4,5]. Wetlands also support levels of biodiversity at rates disproportionate to their area by providing a habitat for numerous species of plants and animals [6]. In recent years, these valuable natural resources have been rapidly degraded by human activities worldwide, such as urbanization and increased agricultural production [7]. Additionally, wetlands are currently being negatively influenced by climate change [1]. Thus, it is important to protect these valuable resources using realistically implemented managerial plans and the establishment of well-defined policies and laws.

The desire to alleviate wetland losses has manifested in an international treaty (Reference [8]), various governmental policies, and inventory initiatives around the globe $[1,9,10]$. To do this, remote sensing methods are necessary because field-based techniques are both too expensive and too labor intensive. Remote sensing satellites that acquire medium to high spatial resolution and multi-channel imagery over a large area can be effectively applied to classify wetlands. Moreover, multi-temporal satellite images are helpful for improving the classification accuracy of these dynamic landscapes and monitoring their changes over time [11-14]. Satellite data have been applied to create wetland inventory systems in different countries. As an example, Fournier et al. [15] suggested that the Canadian Wetland Inventory (CWI) should be completed using satellite imagery, specifically RADARSAT and Landsat. Since the CWI was proposed, most provinces have contributed at least partial wetland inventories to the effort, following the guidance of the Canadian Wetland Classification System (CWCS, Reference [16]). The CWCS categorizes Canadian wetlands into five classes, bog, fen, marsh, swamp, and shallow water. The functions and ecological characteristics of wetlands (e.g., soil, water source, water table, vegetation, $\mathrm{pH}$, and nutrition conditions) were considered in these classifications. Based on the CWI regulations, all wetland classification activities should be based on the specifications defined in the CWCS. These studies were mostly conducted using different types of satellite data over relatively small areas [7,11,17-20].

Processing big data is the biggest challenge when implementing a wetland inventory system at provincial or national scales, especially when it is the wetlands of the second largest country in the world requiring classification. To this end, numerous satellite images should be processed and classified over a large area, which is not efficient via common image classification software packages. To tackle this issue, Google has developed a cloud-based platform, Google Earth Engine (GEE). One of its key advantages is the ability to process large geospatial datasets and classify land covers over large areas [21]. Users can access free satellite datasets, such as those acquired by Landsat-8, Sentinel-1 and -2 , and MODIS. There is no need to download these terabyte-scale, large size datasets to local computers since they can be directly and efficiently processed within GEE. Many products have also been preprocessed and can be easily inserted into user-defined algorithms. In addition, many algorithms, such as image classifiers and cloud masking methods, have been previously implemented and can be imported and modified by users [21,22]. To date, researchers from different countries have utilized GEE for a variety of large-scale applications. For instance, Dong et al. [23] applied multi-temporal Landsat-8 data to map paddy rice in northeastern Asia annually and analyzed the changes within GEE. They reported that GEE along with their proposed phenology- and pixel-based paddy rice mapping (PPPM) method had a high potential to map paddy rice over large areas with the user and producer accuracies of $92 \%$ and $73 \%$, respectively. Moreover, Chen et al. [24] mapped mangrove forests all over China using GEE and a combination of Landsat-7 and -8, and Sentinel-1 
images. Their results showed that the normalized difference vegetation index (NDVI), modified normalized difference water index (MNDWI), and Vertical transmit and Horizontal receive (VH) polarization had the highest potential for identifying mangrove forests. Finally, Xiong et al. [25] integrated pixel- and object-based methods in GEE to classify crops over the African continent using a combination of Landsat- 8 and Sentinel-2 images acquired between 2015 and 2016. They obtained an overall accuracy of $94 \%$ and reported that the total net cropland area over Africa was 313 Mha in 2015.

It is estimated that Canada contains circa $25 \%$ of global wetlands and that circa $13 \%$ of Canada's terrestrial area $\left(1.3\right.$ million $\left.\mathrm{km}^{2}\right)$ is covered by wetlands $[16,26]$. Thus, it is pivotal to identify the location and extent of wetlands throughout Canada and to monitor their changes, including gains and losses over time. The first study addressing large-scale wetland mapping in Canada was reported by Wulder et al. [10]. These authors mapped non-treed and treed wetlands (two wetland classes) plus several non-wetland classes over Canada's forested ecosystems ( $>6.5$ million km²: 65\% of Canada's total area) using 33 years of Landsat data and several preprocessing and classification algorithms. More recently, Amani [27] used Landsat-8 imagery to classify wetlands in one of the Canadian provinces (Newfoundland and Labrador). All the classification steps were processed within GEE and they proposed that their method could be efficiently used to produce wetland inventory systems for other Canadian provinces and for all of Canada.

As discussed above, most of the previous studies about wetland classification in Canada have been conducted over relatively small areas and many of them are also not based on the CWCS specifications. Therefore, in this study, we addressed the limitations of previous studies and extended the work conducted by Amani [27] by proposing a more efficient approach to produce the first Canada-wide wetland map. The structure of the manuscript can be summarized by the following: (1) All of Canada is classified; (2) the classification is based on the guidelines provided by the CWCS (five classes) to create the CWI; (3) the major non-wetland classes found in Canada are considered in the final map to obtain more reliable information about the location and extent of wetlands throughout the country; (4) a composite of Landsat- 8 imagery collected from 2016 to 2018 is used to generate classifier inputs, thus, enabling the production of a Canada-wide wetland map every three years, and the ability to monitor changes; (5) using GEE, the most time- and cost-efficient approach for creating a CWI is proposed.

\section{Study Area and Datasets}

\subsection{Study Area}

The study area was all of Canada, with an area of 9.985 million $\mathrm{km}^{2}$ (Figure 1) extending from the Pacific Ocean in the west to the Atlantic Ocean in the east. Canada has different climate types (e.g., tundra, subarctic, and humid continental) due to its size. Most areas of the Canadian territories (i.e., the Northwest Territories, Nunavut, and Yukon) are covered by rock, ice, and permafrost, as well as wetlands. However, the Canadian provinces (i.e., Newfoundland and Labrador, Prince Edward Island, Nova Scotia, New Brunswick, Quebec, Ontario, Manitoba, Saskatchewan, Alberta, and British Columbia) are mostly dominated by forests, croplands, and wetlands. Although the number and type of wetlands varies within the different provinces and territories of Canada most of the wetland classes specified by CWCS can be found in all Canadian provinces $[10,16,28]$. 


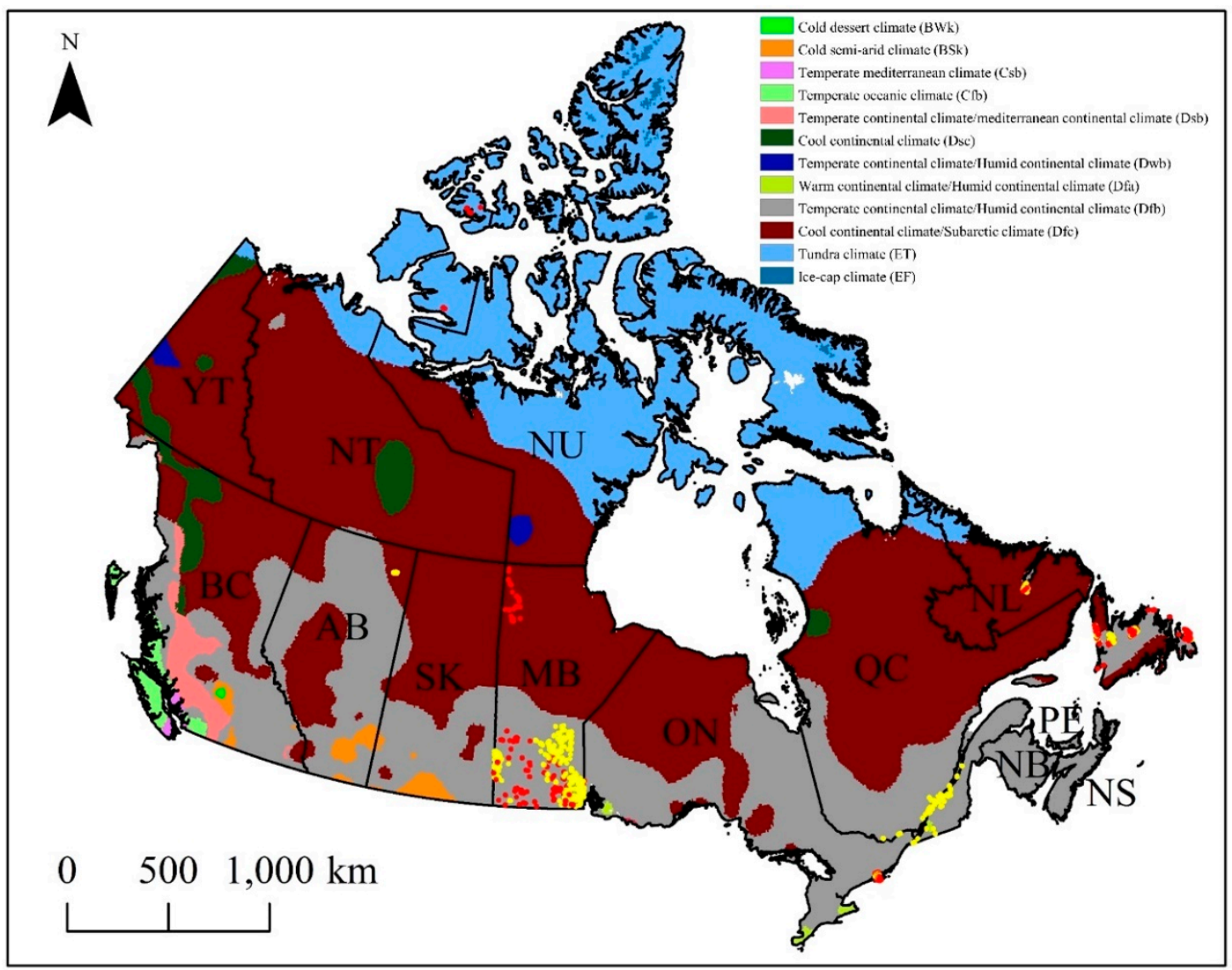

Figure 1. Map of Canada based on the Koppen climate classification [29] and the distribution of field samples. The wetland and non-wetland samples are represented by the yellow and red dots, respectively (NL_Newfoundland and Labrador; PE—Prince Edward Island; NS—Nova Scotia; NB-New Brunswick; QC-Quebec; ON-Ontario; MB-Manitoba; SK-Saskatchewan; AB-Alberta; BC-British Columbia; YT-Yukon Territory; NT-Northwest Territories; and NU—Nunavut).

\subsection{Field Data}

Field data were collected and provided by different organizations from the provinces of Newfoundland and Labrador, Quebec, Ontario, Manitoba, and Alberta. As is shown in Figure 1, most of the field samples, especially those of wetlands, were collected from the temperate continental climate region. Additionally, there were several samples collected from the cool continental climate region. The field data were not in a consistent format, and some of the field work was not conducted in accordance with the CWCS guidelines. Therefore, all the field data (polygons) were initially pre-processed to ensure consistency. Several of the datasets were also point-based and, thus, were converted to polygons by visual analyses of high spatial resolution imagery available in ArcGIS ${ }^{\mathrm{TM}}$ and Google Earth ${ }^{\mathrm{TM}}$. Table 1 describes all wetland and non-wetland classes considered in this study and Table 2 demonstrates the number and area of field samples (polygons) for each of these classes. Field data from five non-wetland classes were also used in this study along with the five wetland categories. This was important for reducing the misclassification of non-wetland categories as wetland classes and for obtaining a more accurate and reliable wetland map. As demonstrated in Table 1, most of the wetland field samples were from Manitoba, Quebec, and Newfoundland and Labrador, respectively. The total area of all wetland and non-wetland field samples, including the samples created for the barren class from other regions (see the notes in Table 2) were approximately $52,691 \mathrm{~km}^{2}$, covering about $0.0053 \%$ of the entire area of Canada. 
Table 1. The characteristics of wetland and non-wetland classes classified in this study.

\begin{tabular}{cc}
\hline Class & Description \\
\hline Bog & Ombrogenous peatland with organic soil, byrophytes and graminoid vegetation, and \\
mostly standing water.
\end{tabular}

Table 2. Field samples (polygons) from different Canadian provinces.

\begin{tabular}{|c|c|c|c|c|c|c|c|c|c|c|c|c|}
\hline \multirow[b]{2}{*}{ Class } & \multicolumn{2}{|c|}{ NL } & \multicolumn{2}{|c|}{ QC } & \multicolumn{2}{|c|}{ ON } & \multicolumn{2}{|c|}{ MB } & \multicolumn{2}{|c|}{$\mathbf{A B}$} & \multirow[b]{2}{*}{$\begin{array}{c}\text { Total \# } \\
\text { Polygons }\end{array}$} & \multirow[b]{2}{*}{$\begin{array}{c}\text { Total } \\
\text { Area }\left(\mathbf{k m}^{2}\right)\end{array}$} \\
\hline & $\begin{array}{c}\# \\
\text { Polygons }\end{array}$ & $\begin{array}{c}\text { Area } \\
\left(\mathbf{k m}^{2}\right)\end{array}$ & $\begin{array}{c}\# \\
\text { Polygons }\end{array}$ & $\begin{array}{c}\text { Area } \\
\left(\mathbf{k m}^{2}\right)\end{array}$ & $\begin{array}{c}\# \\
\text { Polygons }\end{array}$ & $\begin{array}{c}\text { Area } \\
\left(\mathbf{k m}^{2}\right)\end{array}$ & $\begin{array}{c}\# \\
\text { Polygons }\end{array}$ & $\begin{array}{c}\text { Area } \\
\left(\mathbf{k m}^{2}\right)\end{array}$ & $\begin{array}{c}\# \\
\text { Polygons }\end{array}$ & $\begin{array}{c}\text { Area } \\
\left(\mathbf{k m}^{2}\right)\end{array}$ & & \\
\hline & \multicolumn{12}{|c|}{ Wetland } \\
\hline Bog & 45 & 10.6 & 12 & 25.7 & 0 & 0.0 & 12 & 51.3 & 0 & 0.0 & 69 & 87.6 \\
\hline Fen & 32 & 4.2 & 5 & 7.4 & 0 & 0.0 & 17 & 75.2 & 0 & 0.0 & 54 & 86.8 \\
\hline Marsh & 70 & 8.5 & 7 & 27.6 & 27 & 10.5 & 8 & 47.6 & 5 & 15.4 & 117 & 109.6 \\
\hline Swamp & 28 & 2.0 & 16 & 25.6 & 18 & 18.4 & 14 & 49.2 & 11 & 8.1 & 87 & 103.3 \\
\hline Deep Water & 41 & 11.4 & 0 & 0.0 & 0 & 0.0 & 1 & 49.3 & 0 & 0.0 & 42 & 60.7 \\
\hline Forest & 237 & 15.1 & 0 & 0.0 & 40 & 6.9 & 33 & 66.9 & 0 & 0.0 & 310 & 88.9 \\
\hline Grassland & 45 & 2.9 & 0 & 0.0 & 0 & 0.0 & 15 & 77.8 & 0 & 0.0 & 60 & 80.7 \\
\hline Cropland & 16 & 0.8 & 0 & 0.0 & 92 & 14.7 & 12 & 50.3 & 0 & 0.0 & 120 & 65.8 \\
\hline Barren ${ }^{*}$ & 257 & 19.6 & 0 & 0.0 & 0 & 0.0 & 60 & 34.2 & 0 & 0.0 & 317 & 53.8 \\
\hline Total & 825 & 78.2 & 49 & 122.3 & 177 & 50.5 & 391 & 524.1 & 16 & 23.5 & 1,458 & 798.6 \\
\hline
\end{tabular}

\subsection{Satellite Data}

Multi-temporal Landsat-8 data collected between 1 May and 30 November in 2016, 2017, and 2018 were used in this study. Since wetlands are dynamic, multi-temporal images improve classification accuracy. In fact, using multi-date optical data, it is possible to find imagery by which various wetland types are distinguishable. For instance, there is no vegetation within the shallow water areas in early spring (e.g. April). Hence, this class could most likely be confused with the deep water class in terms of the spectral response at that time of year. However, in late summer (e.g. August), when the vegetation in shallow water areas reaches peak biomass, its spectral characteristics differ from those of deep water. In this study, the visible, near infrared (NIR), and shortwave infrared (SWIR) bands of Landsat-8 (six bands in total) with a spatial resolution of 30 meters were employed as inputs to the 
classifier. A total of 29,456 Landsat-8 images were preprocessed and classified simultaneously in the classification procedure.

\section{Methodology}

All the steps for producing the CWI map, including preprocessing, classification, and accuracy assessment were performed within the GEE platform. Preprocessing included cloud/snow masking and median imagery generation, classification was based on the random forest (RF) algorithm, and accuracy assessment was performed both visually and statistically.

Studies related to satellite image classification have often used the data representing digital number (DN) values without applying any atmospheric correction, which is only suitable for small areas over which the weather is consistent. It is essential to employ surface reflectance values to achieve accurate and reliable classification results for large-scale applications over which the weather conditions can change significantly. This is especially relevant when considering the entire country of Canada, for which climate conditions vary significantly through space and time. Thus, the atmospherically corrected surface reflectance products of Landsat-8 (Tier 1 level, ee.ImageCollection (“LANDSAT/LC08/C01/T1_SR")), prepared by the United States Geological Survey (USGS) and available in GEE, were used in this study. Moreover, cloud and snow masking from optical satellite data are relatively important in areas such as Canada due to the predominantly unfavorable weather conditions. Cloud cover is frequent over Canada and efficiently removing all clouds from Landsat-8 images is challenging. Additionally, a large portion of Canada, especially in the north, is covered by snow most of the year. Both cloud and snow are considered serious challenges in various applications, including the use of optical satellite data over Canada. However, since multi-temporal optical satellite data were adopted in this study, cloud and snow were efficiently masked in GEE. To this end, a GEE JavaScript code using a median ee.Reducer function was applied to all optical imagery to downscale each tile to a single image representing the median of the pixel values with no/least possible cloud and snow covers. A threshold of $<20 \%$ was considered for excluding the images to produce the cloud- and snow-free composite. This approach also removed dark pixels from shadow and very bright pixels from factors such as haze.

The six spectral bands of Landsat-8 (i.e., visible, NIR, and SWIR) were inserted into an RF algorithm to classify wetlands in Canada. RF was employed in this study due to its high potential for mapping land covers such as wetlands $[7,11]$. RF is a non-parametric machine learning classifier that contains an ensemble of decision trees, each of which possess several nodes that divide the input pixels into mutually exclusive groups. The division continues until each node is representative of one of the final classes [31]. RF contains several tuning parameters that should be carefully selected based on several factors, such as the number of training samples, to obtain a high classification accuracy. In this study, the optimum values for these parameters were selected by trial and error and by considering the computational efficiency of the method (see Table 3). It is also worth noting that $50 \%$ of the field samples were randomly used for training the RF algorithm and the other $50 \%$ were retained for accuracy assessment.

Table 3. The optimal values for the tuning parameters of the Random Forest (RF) classifier.

\begin{tabular}{cc}
\hline Parameter Name & Parameter Value \\
\hline Number of decision trees & 80 \\
Number of variables in each node split & 3 (square root of the total number of features) \\
Minimum size of a terminal node & 2 \\
Fraction of the input to bag per tree & 0.5 \\
Number of random seeds & 5 \\
\hline
\end{tabular}

Two types of accuracy assessments were conducted for the final Canada-wide wetland map. First, the map was analyzed and interpreted visually using the World Imagery Basemap available in ArcMap, 
multi-temporal imagery provided in Google Earth, previous wetland classification maps from different provinces, as well as Canada-wide land cover maps and statistics [10,32] to see if the classes visually corresponded to real-world objects. Second, statistical accuracy assessments were performed using the test data (i.e., $50 \%$ of the ground truth data) to obtain indicators of classifier performance via confusion matrices, including independent overall accuracy, kappa coefficient, and producer and user accuracies.

\section{Results}

Figure 2 illustrates the classified wetland map of Canada with a spatial resolution of $30 \mathrm{~m}$, obtained using multi-temporal Landsat- 8 data within the GEE platform. The provincial wetland inventory maps for all provinces can also be extracted based on these results. For instance, Figure 3a,b illustrates the full Newfoundland and Labrador and Ontario wetland maps, respectively. Two zoomed areas of these maps along with the corresponding high-resolution images are also provided in Figure 3 for visual comparison. Visually, most of the classified areas appear to be realistic representations and are supported by the known physical geography of Canada. For instance, by visual comparison of the produced map with Figure 1 and the high-resolution World Imagery Basemap available in ArcMap, it was observed that the water bodies were mapped with reasonable accuracy. In this regard, small water bodies and the regions surrounding large water reservoirs, which are expected to have a shallow depth, were generally correctly classified as shallow water (e.g., compare Figure 3e,f). In the current classifications, the barren class includes rock, sand, gravel, and built-up areas (see Table 1). The territories in Northern Canada are mostly covered with rocks that were correctly classified as barren in Figure 2. There were also other correctly classified barren regions in Figure 2 demonstrating urban areas in the south of the $\mathrm{BC}, \mathrm{AB}, \mathrm{SK}, \mathrm{MB}$ provinces, which are among the most populated areas in Canada according to existing statistics [33]. For example, the urban areas in Ottawa (Figure 3d) and St. John's (Figure 3f) were correctly classified as Barren (Figure 3c,e, respectively). The croplands, which can be identified by their regular shape in aerial imagery, are also mostly found in the south of $\mathrm{BC}$, $\mathrm{AB}, \mathrm{SK}, \mathrm{MB}, \mathrm{ON}$, and QC in the produced Canada-wide wetland map and correspond to statistics of Canadian maps of agricultural operations [34]. For instance, the agricultural areas in the south of Ottawa were mostly identified correctly in the produced wetland map for Ontario (see Figure 3). Furthermore, based on Natural Resources Canada [35], which demonstrates the approximate location of different forests in Canada, forests mostly exist all over NB, the southern part of QC and ON, sparsely in $\mathrm{MB}, \mathrm{SK}$, and $\mathrm{AB}$, and most parts of $\mathrm{BC}$. The same forest pattern was also observed in the produced Canada-wide wetland map (Figure 2).

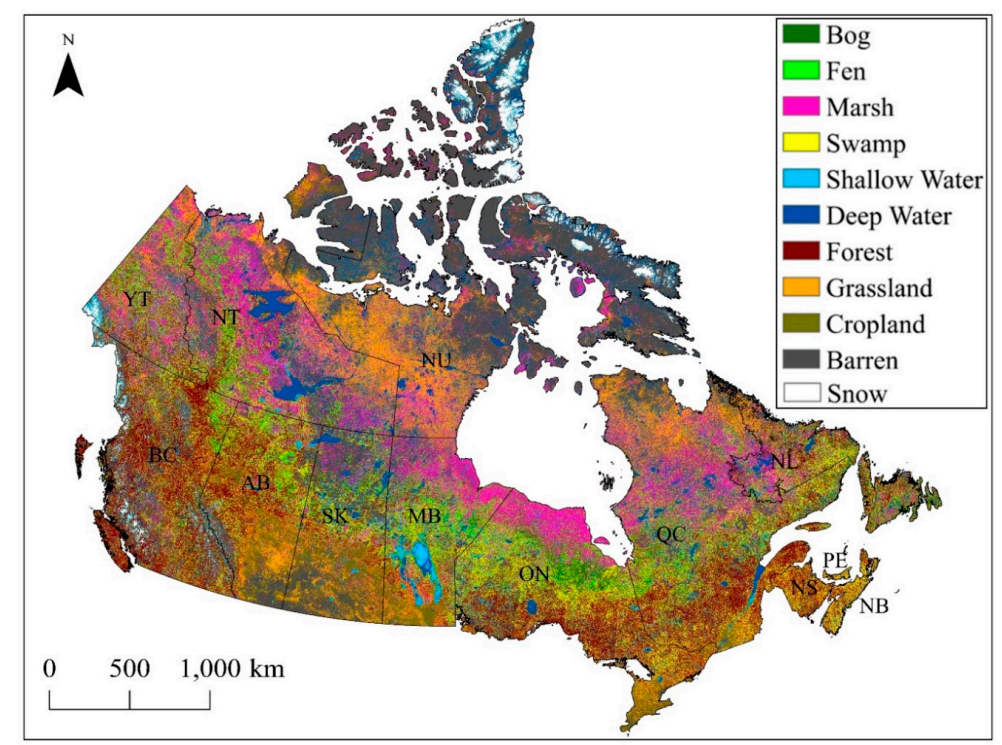

Figure 2. First Canada-wide wetland map. 


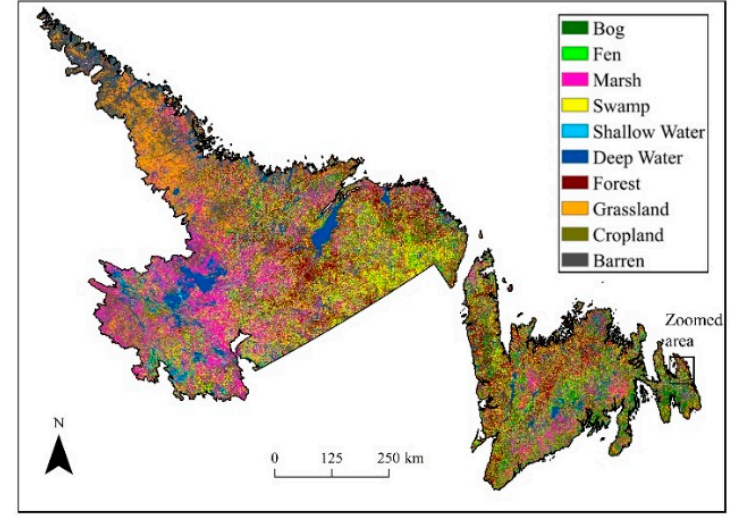

(a)

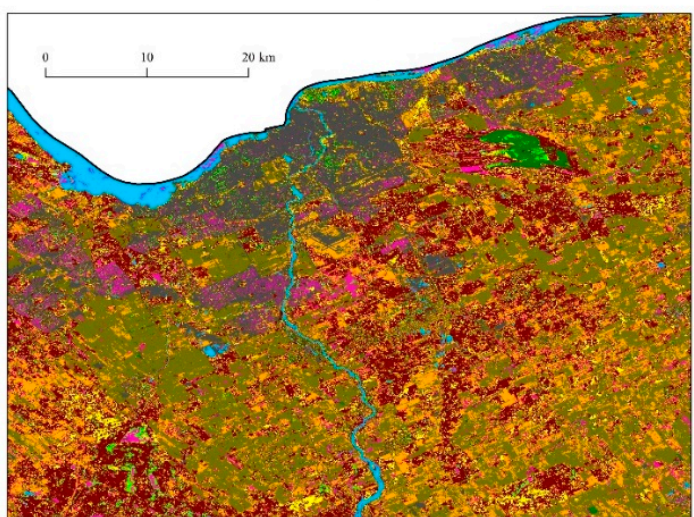

(c)

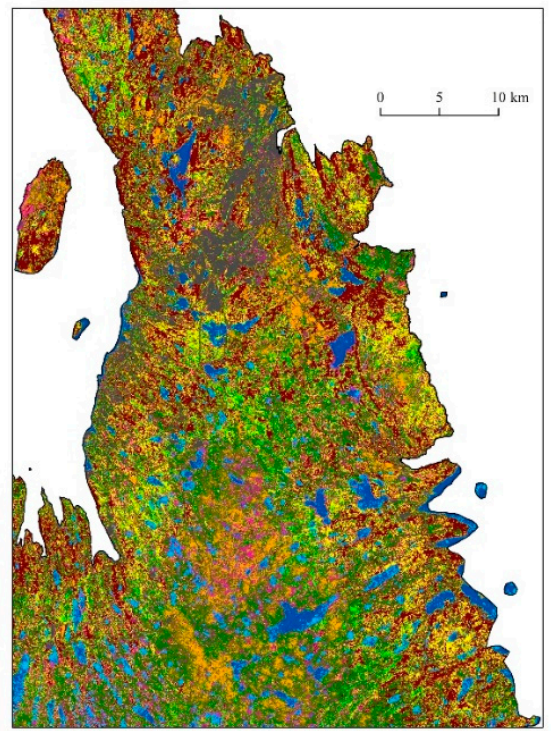

(e)

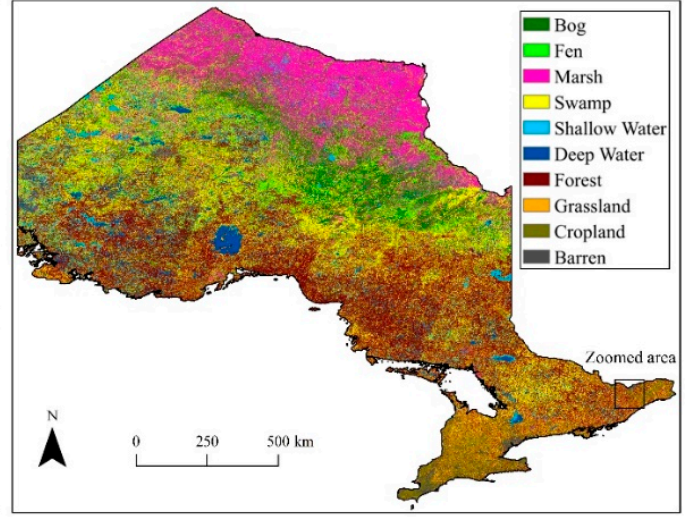

(b)

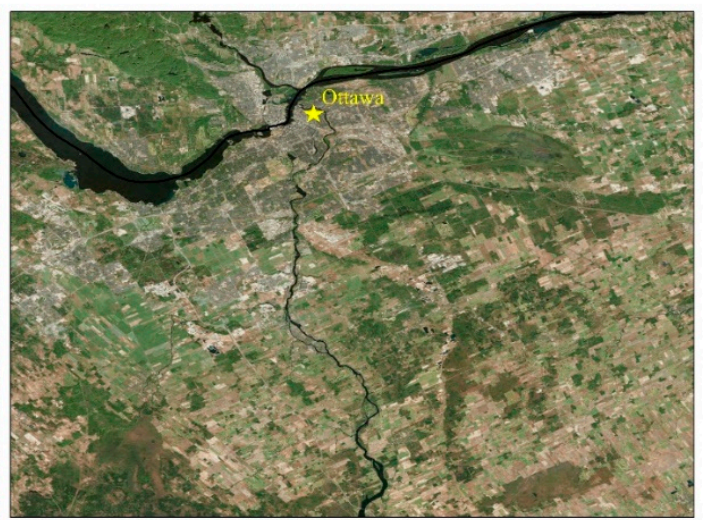

(d)

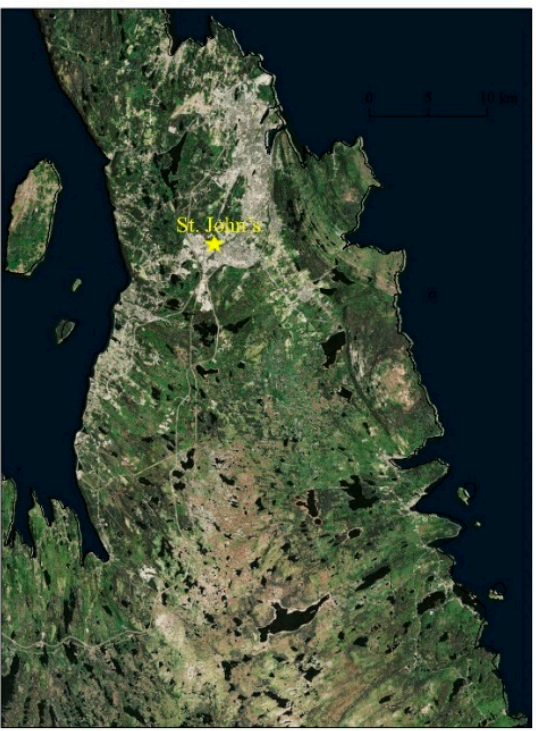

(f)

Figure 3. Provincial wetland inventory maps and zoomed images from two provinces: (a) Newfoundland and Labrador and (b) Ontario. (c) and (d) from Ontario and (e) and (f) from Newfoundland and Labrador demonstrate their visual accuracies.

It was challenging to visually assess the accuracy of wetland identification in the produced CWI map because a comprehensive wetland inventory map for the entire country is not currently available. However, the produced Canada-wide wetland map corresponds well to several older studies (e.g., The Royal Canadian Geographical Society [36] and Environment and Climate Change Canada [26], which were first conducted in 1987 and 2000, respectively) and a recent study [10], which identified 
the location of treed and non-treed wetlands in most parts of Canada. For instance, based on these previous studies, Northern $\mathrm{ON}$ is covered by wetlands, which was also reported in this study (see Figure $3 b$ ). This portion of $\mathrm{ON}$ was classified as marsh in the produced map and corresponds well with Reference [10], which identified this area as mostly non-treed wetlands. It was also estimated that many wetlands are located in Northern AB and Central NT, which is consistent with previous studies $[10,28,36]$.

Table 4 demonstrates the area of Canada occupied by different wetland and non-wetland classes. It was estimated in this study that $36 \%$ and $64 \%$ of the total area of Canada $\left(3,650,798 \mathrm{~km}^{2}\right.$ and $6,459,990 \mathrm{~km}^{2}$, respectively) are covered by wetlands and non-wetlands, respectively. The most dominant wetland classes were marsh and swamp covering approximately $12 \%$ and $8 \%$ of Canada, respectively. Peatlands (i.e., bog and fen), which are important for carbon storage, also cover a large portion of Canada (about 10\%). Regarding non-wetland classes, barren (22\%), forest (15\%), and grassland $(11 \%)$ cover most parts of Canada.

Table 4. Area of each wetland and non-wetland class in Canada based on the CWI map produced in this study.

\begin{tabular}{ccc}
\hline Class & Area $\mathbf{( k m}^{\mathbf{2}} \mathbf{)}$ & \% of Canada \\
\hline & Wetland & \\
\hline Bog & 375,416 & 3.71 \\
Fen & 671,344 & 6.64 \\
Marsh & $1,190,960$ & 11.78 \\
Swamp & 853,734 & 8.44 \\
Shallow Water & 559,344 & 5.53 \\
\hline Total (wetland) & $3,650,798$ & 36.1 \\
\hline & Non-wetland & \\
\hline Deep Water & 673,563 & 6.66 \\
Forest & $1,565,731$ & 15.46 \\
Grassland & $1,062,753$ & 10.51 \\
Cropland & 562,112 & 5.60 \\
Barren & $2,265,214$ & 22.40 \\
Snow & 330,617 & 3.30 \\
\hline Total (non-wetland) & $6,459,990$ & 63.93 \\
\hline
\end{tabular}

Figure 4 illustrates the percentage of wetlands versus non-wetlands in all Canadian provinces and territories. A large portion of each province is covered by wetlands. For example, it was estimated in this study that more than half of NL, NS, ON, and MB are covered by wetlands. In terms of percentage, NU, BC, and SK had the smallest wetland areas, respectively. This illustrates the importance of wetland conservation in Canadian provinces via practical polices.

Table 5 demonstrates the accuracy of wetland classification in the Canada-wide map (Figure 2). The overall accuracy and kappa coefficient for this classification were $71 \%$ and 0.67 , respectively. Moreover, the average producer and user accuracies for wetland classes exclusively were $66 \%$ and $63 \%$, respectively. This level of accuracy is reasonable considering the immense area classified in this study, the low cost of the study, and the computational efficiency of the proposed method. As is clear, the accuracies for the non-wetland classes were generally higher than those of wetland classes, with average producer and user accuracies of $78 \%$ and $81 \%$, respectively. This was because non-wetland classes are more spectrally distinguishable than wetland classes. In this regard, the classification of deep water and barren had the highest accuracies. 


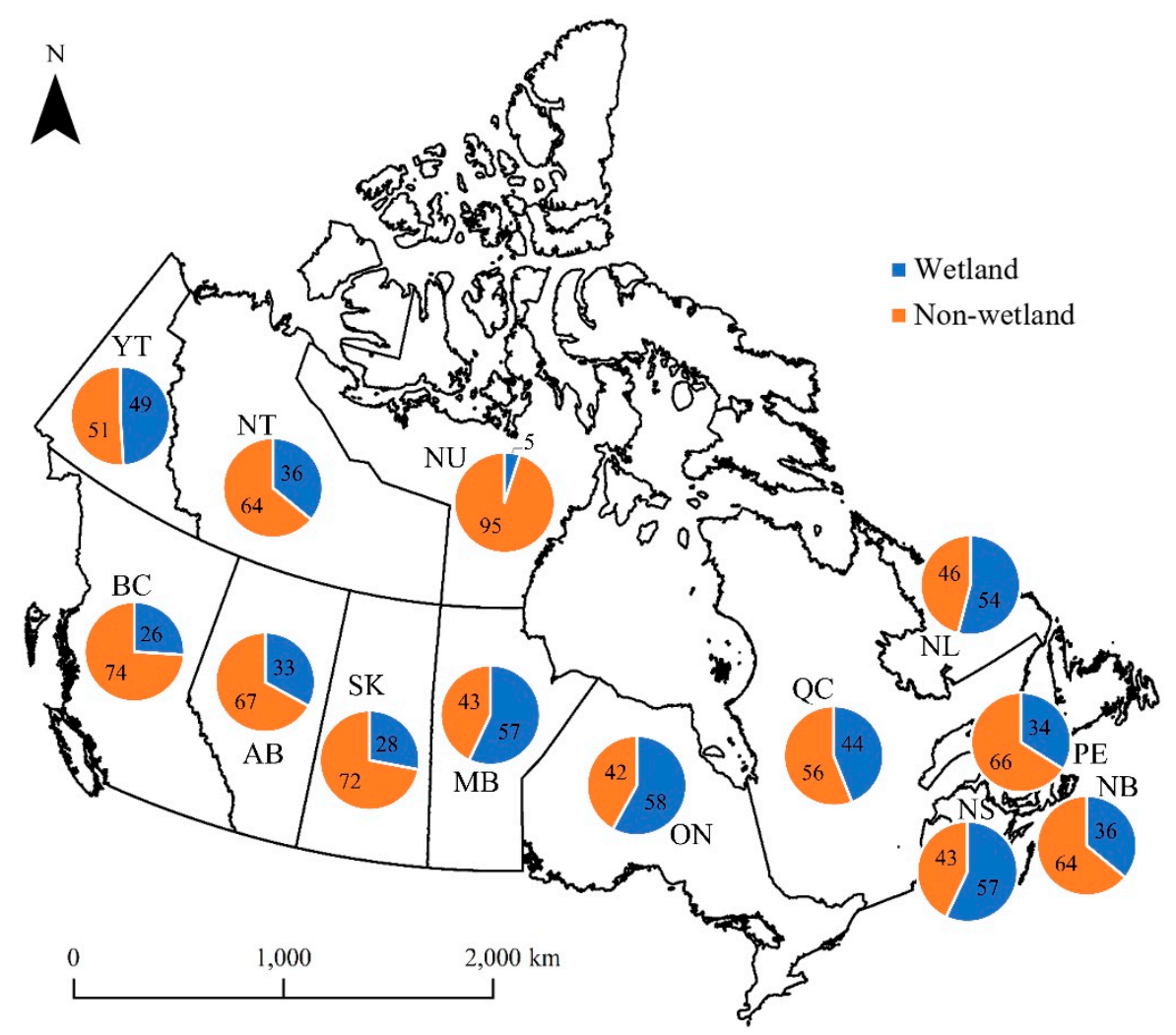

Figure 4. Percentage of wetland and non-wetland areas in different Canadian provinces.

Table 5. The producer and user accuracies of wetland and non-wetland classes obtained from the Canada-wide wetland map. The overall accuracy and kappa coefficient for this classification were $70.6 \%$ and 0.67 , respectively. The classification accuracy is based on the pixels in the classified map, indicating that $70.6 \%$ of all ground truth pixels were correctly identified in the final CWI map.

\begin{tabular}{ccc}
\hline Class & Producer Accuracy (\%) & User Accuracy (\%) \\
\hline Bog & Wetland & \\
Fen & 69.3 & 67.0 \\
Marsh & 51.6 & 60.1 \\
Swamp & 72.4 & 64.2 \\
Shallow Water & 61.6 & 59.8 \\
Average & 76.0 & 64.2 \\
\hline & 66.2 & 63.1 \\
\hline Deep Water & Non-wetland & \\
Forest & 96.8 & 75.2 \\
Grassland & 70.6 & 85.9 \\
Cropland & 62.2 & 62.3 \\
Barren & 72.6 & 84.6 \\
\hline Average & 90.0 & 80.6 \\
\hline
\end{tabular}

\section{Discussion}

There are several factors affecting the accuracy of the produced CWI map; they are discussed in the following section. 


\subsection{Wetland Complexity}

Wetlands are inherently complex environments that hinder the achievement of higher classification accuracies using satellite imagery compared to other land covers regardless of the data used. The main complexities of wetland environments are discussed below.

First, wetland plant species have several spectral similarities due to their biophysical and biochemical characteristics $[30,37,38]$. Therefore, when analyzing the values of field samples for different wetland classes, similar trends are observed. For example, Figure 5 illustrates the distribution of the values of field samples for five wetland classes obtained from the NIR band of Landsat- 8 using violin plots. Clearly, wetlands have similar values especially for vegetated wetland classes. As another example, the Bog and Fen classes share several ecological similarities (see Table 1). They have similar vegetation and soil types, but they are slightly different in terms of saturation and hydrological characteristics. These two types of wetlands are often visually similar, making it difficult to distinguish them in the field (Figure 6a) and, in turn, to use remote sensing analysis (Figure 6b). Consequently, they have sometimes been classified as one wetland class (i.e. peatlands) in previous studies. Based on the information provided in Table 1, these two wetland species contain similar spectral characteristics.

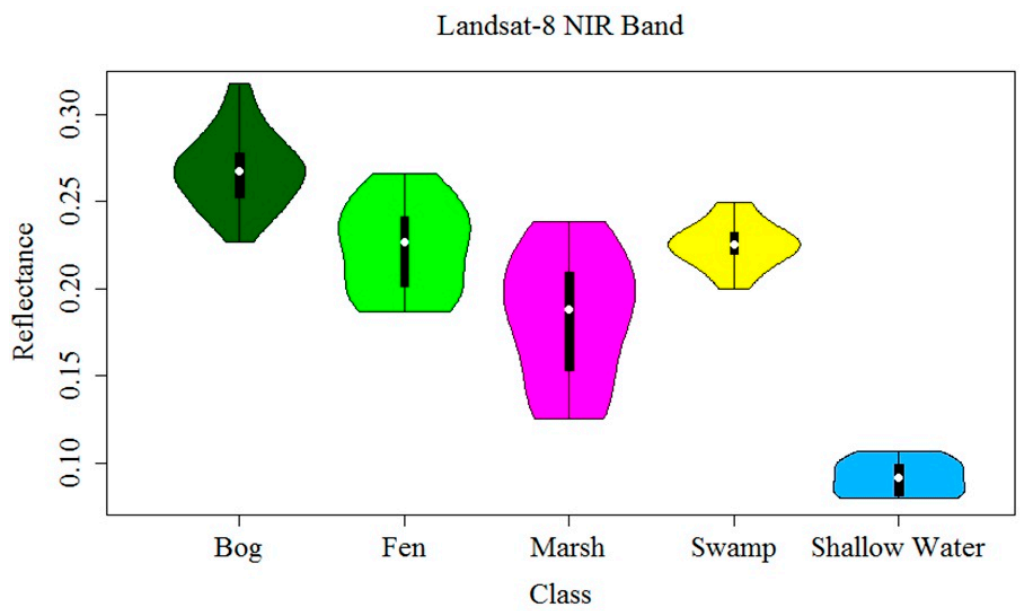

Figure 5. Violin plots of the wetland classes from the Landsat-8 Near Infrared (NIR) band. The white dot, thick black bar in the center and thin black line indicate the median value, interquartile range, and $95 \%$ confidence interval, respectively.

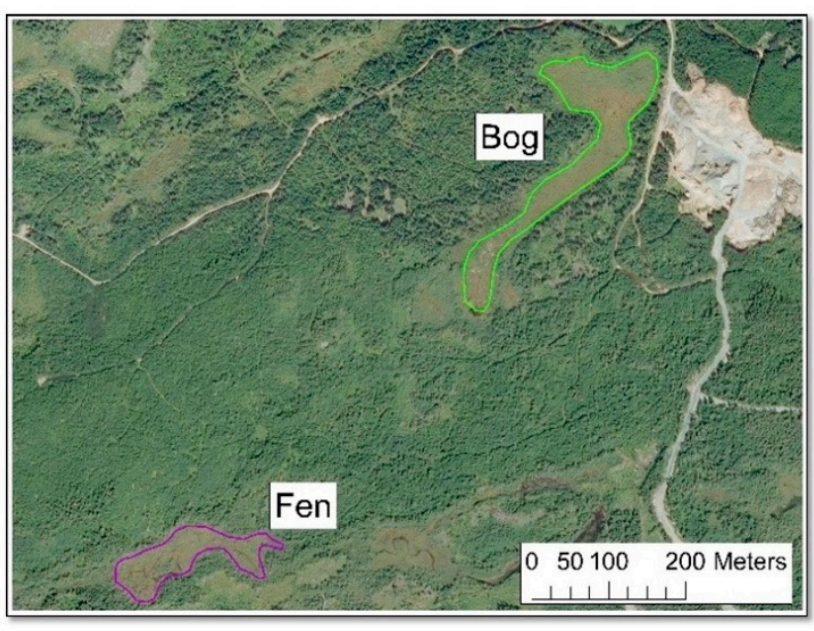

(a)

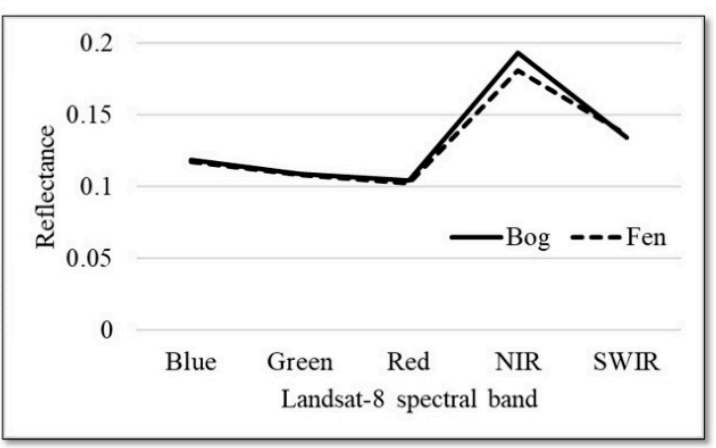

(b)

Figure 6. (a) Bog and fen classes, (b) spectral signature of the bog and fen classes, obtained from the field samples and Landsat- 8 images. This illustrates how the spectral signatures of these two classes are superimposed and difficult to discriminate using the spectral bands of Landsat- 8 imagery. 
Second, even a single wetland class can be classified into several subclasses [16]. For instance, the Enhanced Wetland Classification System (EWCS) [37] divides the five main wetland classes specified by the CWCS, into 19 subclasses. Thus, when analyzing the spectral signature of a particular wetland class, the spectral information of different field samples from that wetland class can vary considerably and sometimes follow a multimodal shape [30]. For example, the marsh class is divided into two subclasses in the EWCS (Figure 7a): (1) meadow marsh, which is mostly out of water and dominated by sedges and grasses, and (2) emergent marsh, which is mostly inundated and dominated by flood tolerant hydrophytic vegetation such as cattail and rushes. Consequently, a bimodal signature was observed when analyzing the spectral characteristics of the field samples of the marsh class (Figure $7 \mathrm{~b}$ ). Therefore, an important step prior to performing separability analyses and wetland classification is to analyze the variation of field samples within each wetland class. When the variance of field samples obtained for a class in a spectral band decreases, the wetland classification is more reliable [30].

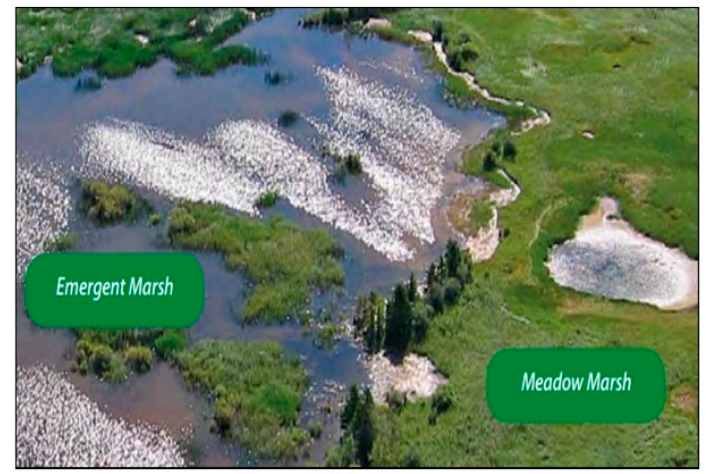

(a)

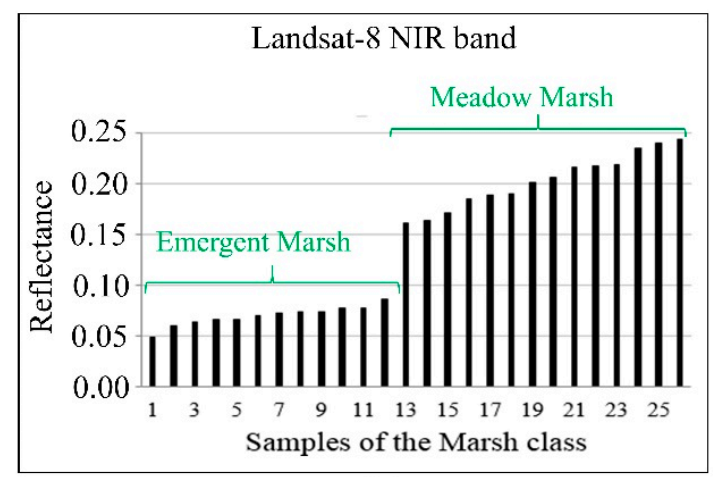

(b)

Figure 7. (a) Two subclasses of the marsh class, (b) spectral values of the field samples of the marsh class obtained from the Landsat- 8 NIR band.

Third, because of the dynamic nature of wetlands, they can change significantly over time [39]. Therefore, their spectral characteristics differ as their vegetation cycles. For instance, a wetland in August (a dryer month) appears different from a that in June (a wetter month) in both field and satellite imagery, particularly in the case of highly saturated wetlands, such as marsh or shallow water. For example, marsh is brown in spring, while it is green and elevated in summer (Figure 8).

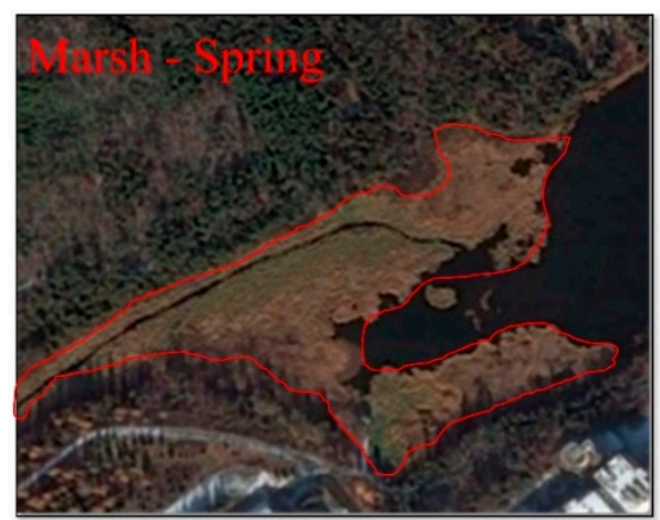

(a)

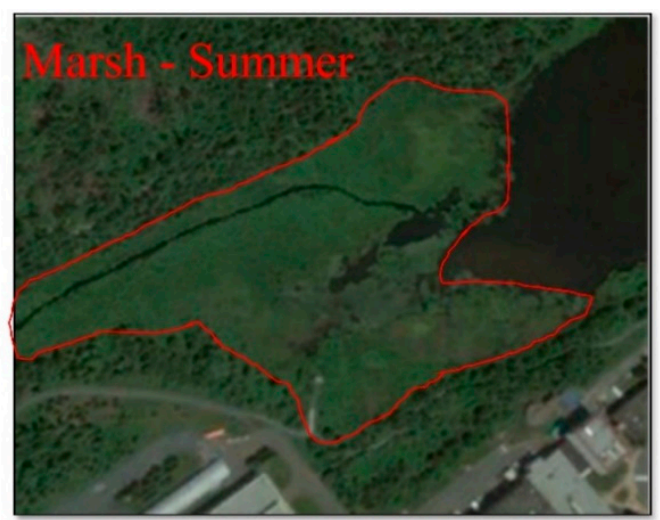

(b)

Figure 8. A marsh in (a) spring and (b) summer. In spring, vegetation is dry, while it is fully grown and elevated in summer. The images were produced using three visible bands of Landsat-8 (Band 2: blue, Band 3: green, Band 4: red). 


\subsection{Field Data}

Although the optimum number of field samples for training machine learning algorithms and accuracy assessment is dependent on several factors, including the number and distribution of classes [40], more field samples result in higher and more reliable classifications [12]. In the present study, the number of field data were considerably low compared to the total area of Canada (i.e., $0.0053 \%$ of the entire area of Canada, see Table 1 ). To obtain a higher classification accuracy, more wetland field data are required. In addition, more field samples of non-wetland classes are required to obtain a more reliable map of wetlands. These field data should be collected from different provinces and various climate zones to represent the characteristics of wetland and non-wetland classes across Canada. For example, as is clear from Figure 1, most of the field samples in this study were collected from mid and eastern Canada (a temperate continental climate region). It is necessary to apply field data collected from other areas to improve the accuracy of the CWI map. However, it should be noted that field data collection is time consuming and costly, especially in the case of wetlands because they are generally located in remote locations.

Furthermore, the field data in this study were collected in different years, ranging from 2000 to 2017. This temporal disparity across the field data collections as well as between the data collection and image acquisition could also cause uncertainty in the classification. This temporal difference is more important for the field samples near the urban areas because many nearby wetlands are gradually replaced or fragmented by man-made land covers, such as croplands, buildings, and roadways.

Moreover, boundary delineation for each field sample is an important step in the preparation of field samples and can increase uncertainty due to unclear and fuzzy wetland boundaries [41]. Therefore, the boundaries should be conservatively determined around wetlands to avoid transitional areas. The boundary delineation was conducted by several operators in this study, who may have used different measures for this purpose. This was more important for some classes, such as shallow water, the discrimination of which from deep water is challenging. The best solution for reducing the uncertainty in boundaries for these two classes is collecting the bathymetric data during the field surveys and selecting the water bodies with less than $2 \mathrm{~m}$ as shallow water and the rest as deep water based on the CWCS. However, this requires extensive field works and, consequently, the delineation between these two classes is usually performed by visual analysis and the ancillary information collected during field surveys. Finally, it should be noted that the uncertainty in the boundaries of the samples could also have affected the classification accuracy in this study.

In summary, it should be noted that the quantity, quality, and geographic sampling distribution of field data affects the classification accuracy considerably. The reason for the low accuracy of some classes in this study was directly related to the number of training data available for those classes and, thus, more field data should be included in future studies. For example, it was observed that most field samples for the marsh class were emergent marshes that have a spectral signature similar to that of the shallow water class. This caused many shallow water areas to be incorrectly classified as marsh. Moreover, it was observed that several deep water regions were misclassified as shallow water. For example, Lake Winnipeg and Cedar Lake in Manitoba, which are deep water bodies, were wrongly classified as shallow water (see Figure 2). Finally, there was confusion between forest and swamp, and due to uncertainty in several field samples of the swamp class, it is expected that many forests were incorrectly identified as swamp. For instance, it was observed that a large area of NS and NB were incorrectly classified as swamp when they were expected to be forest.

\subsection{Satellite Data}

In this study, only images captured by Landsat- 8 were used to produce the first Canada-wide wetland map. However, it is accepted that a combination of optical, SAR, and high-resolution DEM data (e.g., produced from LiDAR data) is the optimal scenario for the delineation of wetland classes to produce the highest possible classification accuracy $[7,13,42,43]$. Therefore, future studies should combine free Landsat-8, Sentinel-1, Sentinel-2, and appropriate DEM data available in GEE to improve 
the classification accuracy of the current CWI map. Finally, it is worth noting that the Canadian RADARSAT Constellation Mission (RCM) will be launched in 2019 and the corresponding data will help to improve the accuracy of wetland mapping and monitoring. RCM will offer different beam modes with various spatial resolutions ranging from $3 \mathrm{~m}$ to $100 \mathrm{~m}$. Specifically, the circular-linear compact polarimetry mode of RCM will enable users to extract and apply different decomposition methods for wetland mapping. Moreover, this satellite offers a better temporal resolution (4 day revisit time) compared to the two previous Canadian SAR systems (i.e., RADARSAT-1 and -2) and, therefore, will facilitate the monitoring of wetlands [44].

\subsection{Input Features}

A common approach for increasing image classification accuracy is extracting more features from the satellite data and including the optimal features in the classification. For instance, the NDVI and NDWI have been extensively used to improve the accuracy of wetland classification $[9,30]$. Moreover, the high potential of the red edge band for wetland discrimination has been extensively discussed $[1,9,30,39]$. Based on the availability of the surface reflectance data of Sentinel-2 in GEE in the near future, this band can be incorporated in large-scale classifications to improve the accuracy. In addition, various SAR features, especially ratio features can be helpful in wetland classification. For example, co-polarizations are important for the detection of flooded wetlands and cross-polarization is useful for the separation of woody and herbaceous wetlands (e.g., swamp and marsh, respectively, Reference [1]). Finally, it has been extensively reported that textural features are valuable in terms of increasing wetland classification accuracy $[1,45]$. These texture features can be extracted from both optical and SAR data. Therefore, future studies should consider including these features in subsequent classification projects.

\subsection{Classification Method}

A pixel-based RF algorithm was used in this study to produce the preliminary CWI map. Recent studies on satellite image classification suggest that pixel-based approaches have several disadvantages when using high and medium spatial resolution data [11,20,25,42]. However, for these types of images, object-based classification methods enable the use of spatial information, the extraction of additional features (e.g., mean, variance), and the reduction of the dataset. Thus, object-based methods may result in more accurate wetland classification compared to pixel-based techniques. However, the segmentation should be carefully performed during an object-based method to produce objects with appropriate size for classification. For example, the minimum mapping unit for the CWI is 1 ha (approximately 9 pixels of Landsat-8) and, therefore, if the objects generated by an object-based method do not have the proper size, many small wetlands will be missed through the classification procedure. Although the segmentation methods within GEE have not yet been developed, there are a few simple segmentation algorithms, such as simple non-iterative clustering (SNIC), which can be employed for object-based classifications. The efficiency and accuracy of the object-based methods available within GEE for mapping significantly large areas like Canada should be investigated in future studies. Additionally, it was suggested to develop more advanced classification algorithms to achieve a higher accuracy. For instance, Amani et al. [20] developed a multiple classifier system (MCS), combining various machine learning algorithms, to improve classification accuracy compared to using a single classifier, such as RF. However, the computational complicity of the proposed methods should always be considered prior to selecting a classification method.

\subsection{Merging/Splitting Non-Wetland Classes}

It was observed that several cropland areas were confused with grassland and barren areas in this study. This was because the cropland class can have spectral similarities with the grassland and barren classes, especially during growing and harvesting seasons, respectively. Thus, it has been suggested that merging some of these classes in future CWI maps could produce a more accurate classification 
result. On the other hand, based on the notes provided in Table 1, several non-wetland classes were merged prior to classification in this study. For instance, the three forest types of deciduous, coniferous, and mixed wood were considered one class - forest. However, based on various applications, the non-wetland classes considered in this study can be further subdivided. For example, the urban and barren classes, which were combined in this study, comprise different land uses and could be separated in future studies. Finally, it should be noted that merging or splitting non-wetland classes will add to the confusion between wetland and non-wetland classes, which in turn influences the accuracy of the wetland classes. For instance, if barren is considered one single class, it might be confused with some of the wetland classes especially during non-growing seasons when there is no or sparse vegetation. This will result in similarities between the spectral characteristics of some wetlands and barren areas.

\subsection{Estimated Wetland Areas}

Table 2 and Figure 4 provide the estimated wetland areas in Canada and each of the provinces. Previous statistics, such as those provided by the Royal Geological Society of Canada [36], conducted first in 1987, stated that about 1,270,000 $\mathrm{km}^{2}$ (about 13\%) of Canada is covered by wetlands. (It is worth noting that shallow water was not considered part of wetlands in these studies). However, it was estimated in the present study that $36 \%$ of Canada is covered by the five wetland classes specified by the CWCS (see Table 2). The discrepancy between these two statistics demonstrates that, assuming the previous reports were correct, an overestimation occurred in the wetland map produced in this study. This overestimation may be true to some extent. For example, the marsh and swamp areas in the produced CWI map were approximately $12 \%$ and $8 \%$ of the country, respectively, which is possibly too much for the entire country. One reason could be the accuracy of field samples, as discussed in Section 5.2. Conversely, the non-wetland classes were underestimated in the produced map. For example, although the approximate locations of forests were correct, as discussed in Section 4, the area of forests seems to be significantly underestimated. It has been reported that the total area of forests in Canada is approximately $40 \%$ [46], while the forest class occupies only $15 \%$ of the produced map in this study. This potentially demonstrates a considerable confusion between wetlands and forests in the produced map. For example, swamps could be incorrectly identified as forests in this research. However, it is worth noting that swamps, treed bogs, and treed fens might have been also incorrectly classified as forest in the Canada-wide forest maps and, thus, the coverage of forests in Canada might have originally been overestimated. As another example, the statistics show that agricultural lands cover about $7.3 \%$ of Canada [34], while croplands comprise only $5.6 \%$ of the produced map. This could also be because of confusion between cropland/grassland and cropland/barren classes as discussed in Section 5.6. Finally, it should be noted that the existing discrepancies are not only due to errors in the produced map in this study, but may also be partially attributed to flaws in the existing reports as well, namely because they have not been updated and have been mostly produced using methods other than advanced remote sensing techniques. Moreover, shallow water was not considered in their estimation (circa 5-9\%). For instance, based on this report, only 18\% of NL is covered by wetlands while recent studies conducted by advanced remote sensing methods confirm that more than $40 \%$ of this province is covered by wetlands [27]. Consequently, although wetland areas in Canada are probably less than $36 \%$, these natural resources are expected to cover more than $13 \%$ of the total area of this country. In summary, future studies should aim to improve the current preliminary CWI map using the approaches discussed in the six aforementioned subsections. By doing this, it will be possible to investigate how much overestimation and underestimation exists in the current study and previous reports, respectively.

\subsection{Wetland Change Detection}

Although the produced CWI map provides valuable information about the location and extent of wetlands, it can also contribute to understandings of the amount of loss and gain in wetland areas over time. By visually comparing the old field data collected before 2010 and the current satellite imagery, it 
was observed that several wetlands have degraded or been replaced by other land covers mostly due to human activities. For instance, when visually analyzing the field samples collected in 2001 near Winnipeg in Manitoba, it was observed that many wetlands were converted to croplands over time. Therefore, it will be helpful to produce change detection maps indicating the location and extent of wetland degradation or expansion. In this regard, it should be noted that it is not practical to produce wetland maps of the entire country for analyzing wetland changes annually using optical satellite data due to the frequent cloud and snow cover in Canada. Consequently, it is essential to use multi-year optical images to produce a snow- and cloud-free wetland map. For instance, using the Landsat- 8 imagery collected over three years yielded a cloud and snow free map in this study. Thus, in Canada, it is practical to monitor wetland changes approximately every three years using Landsat- 8 data. To monitor wetland changes annually, another approach could be using SAR data (e.g., Sentinel-1) for the cloudy areas and using a combination of optical and SAR satellite data for non-cloudy areas. Finally, it should be noted that the accuracy of the present map is not considerably high for monitoring the changes in wetland areas. Therefore, the classification method should be initially improved based on several suggestions provided in the above subsection and, then, this improved method can be used for operational wetland monitoring with proper accuracy.

\subsection{GEE Limitations}

Several methods, including using more satellite data and input features, as well as using more advanced classification methods were suggested in the above subsections to improve the classification accuracy for the CWI map in future studies. However, it should be noted that not all remote sensing algorithms could be implemented in the GEE platform. Three examples in this regard are discussed in the following: (1) one of the approaches to improving the accuracy of the RF algorithm is using optimum values for the tuning parameters, such as the number of trees. However, it is not possible to increase the values of these tuning parameters within GEE, because this is not computationally possible when a large amounts of field samples are used. Thus, this partially causes a limitation in increasing the accuracy; (2) implementing a segmentation algorithm for the entire country may not be possible due to the high computation associated with this. Thus, using an object-based classification method might not be practical for the production of the Canada-wide wetland map; and (3) users are limited to specific numbers of field samples and input features. For instance, the maximum number of training points in GEE should be approximately less than one million. In fact, adding more datasets reduces the efficiency of the method, and is sometimes not possible. Consequently, a trade-off should always be considered between the efficiency of the method and level of accuracy of large-scale applications. This could partially hinder improvement of the accuracy of the wetland classification for the entire country.

\subsection{Contribution in Other Fields}

The final CWI map was produced solely using satellite data. To make better use of this map, the results should be incorporated into various applications, such as the modeling of important environmental variables and wetland services, the assessment and development of wetland conservation and managerial policies, and the estimation of wetland conditions. For example, wetland maps are often among important input data for modeling carbon storage and methane emissions at a regional and national scale [47,48], with both carbon and methane playing important roles in discussions of climate change. Accurate wetland maps are also necessary for quantifying and qualifying the baseline of and changes to important wetland services [49], such as water quality treatment, water flow moderation, and biological productivity, in which different wetland classes have numerous roles [50]. Swamps, for example, have a high potential for providing water quality treatments compared to that of bogs [50]. Additionally, the produced wetland map can be used to establish baseline information for the current extent of wetlands in Canada, trends in wetland status, the relative extents of differing wetland classes and to establish which wetlands are the rarest versus the most common, all of which can then be used to improve or alter current and future wetland 
policies [50,51]. Finally, this map can be used as an input for assessing wetland conditions [52]. The national wetland condition assessment in the United States, for example, applies the use of the National Wetlands Inventory to examine the condition of the nation's wetlands [53], and a similar approach can be adopted in Canada using the map produced from the current study.

\subsection{Global Wetland Mapping}

In this study, an efficient approach was proposed to create the CWI. The proposed approach should be investigated further to produce a global wetland map. This requires collaboration between various organizations from all countries. Free satellite images with appropriate characteristics for wetland classification, such as those acquired by Lnadsat-8, are available for the entire globe and can be used for this purpose. Moreover, the available algorithms within GEE can be effectively used for worldwide wetland classification. However, there are several limitations in this regard which should be addressed properly. For example, a unique system cannot be applied for wetland classification in all countries because each country/region has specific land cover and wetlands. One solution would be applying the proposed method in different countries considering the specific landscape of that area and mosaicking the results to create a global wetland map. Another limitation is the immense amount of field data which is required for this purpose. This amount of field data cannot be provided without the active collaboration of environmental organization all over the world.

\section{Conclusions}

Wetlands occupy a large portion of Canada and, thus, there is significant national interest in identifying their location and extent across the country and monitoring their changes over time. Although most provinces within Canada have made at the minimum small contributions to create the CWI, there is not currently a Canada-wide wetland inventory system based on the specifications of the CWCS. Therefore, in this study, a method was proposed and implemented within the GEE platform to create a CWI following the CWCS specifications. The CWI map was assessed both visually and statistically. In terms of the visual assessment, several features of the presented map corresponded to the existing reports and statistics, although several differences were also identified and discussed. In terms of the statistical assessment, an overall accuracy of $71 \%$ was reported. This level of accuracy is reasonable considering the immensity of the study area, low cost of the study, and the computational efficiency of the proposed method. Importantly, it was estimated that about $36 \%$ of Canada is covered by wetlands, though this estimation is likely to be high. Additionally, several limitations of the study, including wetland complexity, field data flaws, the classification method, the effects of non-wetland classes, and GEE restrictions were discussed. However, several suggestions to improve the accuracy of the classification in future studies, including using more field data over larger and more diverse geographic regions, as well as using a combination of SAR, optical, and high-resolution DEM data were also provided. The benefits of this study for various fields, including the monitoring of wetland change overtime for the development of protection policies, were also explored. Overall, it was concluded that employing GEE, which can preprocess and classify large amounts of satellite images, is a considerably efficient approach for operational Canada-wide wetland mapping and monitoring.

Author Contributions: Conceptualization, M.A. (Meisam Amani) and B.B.; data curation, M.A. (Meisam Amani), S.M. and S.M.J.M.; formal analysis, M.A. (Meisam Amani), S.M., M.A. (Majid Afshar) and S.M.J.M.; funding acquisition, M.A. (Meisam Amani), W.H. and B.B.; investigation, M.A. (Meisam Amani), M.A. (Majid Afshar) and B.B.; methodology, M.A. (Meisam Amani); project administration, M.A. (Meisam Amani) and B.B.; resources, M.A. (Meisam Amani), S.M., B.B., L.W., S.B., J.M. and C.H.; software, M.A. (Meisam Amani) and M.A. (Majid Afshar); supervision, M.A. (Meisam Amani) and B.B.; validation, M.A. (Meisam Amani), S.M. and M.A. (Majid Afshar); visualization, M.A. (Meisam Amani); writing—original draft, M.A. (Meisam Amani) and S.M.; writing一review and editing, M.A. (Meisam Amani), S.M., M.A. (Majid Afshar), B.B., W.H., S.M.J.M., L.W., S.B., J.M. and C.H.

Funding: This research was funded by Natural Resources Canada under Grant (SC3000679954) to M. Amani and the Engineering Research Council of Canada (NSERC) Discovery Grant to W. Huang (NSERC-RGPIN-2017-04508 and RGPAS-2017-507962). 
Acknowledgments: This project was supported by the Canada Centre for Mapping and Earth Observation of Natural Resources Canada (NRCan). Field data were collected by numerous individuals from various organizations, including Environment and Climate Change Canada (ECCC), Ducks Unlimited Canada (DUC), Northeast Avalon Atlantic Coastal Action Program, the Memorial University of Newfoundland, and the University of Lethbridge. The authors thank all these organizations for their generous support and for providing such valuable datasets.

Conflicts of Interest: The authors declare no conflicts of interest.

\section{References}

1. Mahdavi, S.; Salehi, B.; Granger, J.; Amani, M.; Brisco, B.; Huang, W. Remote sensing for wetland classification: A comprehensive review. GISci. Remote Sens. 2018, 55, 623-658. [CrossRef]

2. Marton, J.M.; Creed, I.F.; Lewis, D.B.; Lane, C.R.; Basu, N.B.; Cohen, M.J.; Craft, C.B. Geographically isolated wetlands are important biogeochemical reactors on the landscape. Bioscience 2015, 65, 408-418. [CrossRef]

3. Carter, V. An overview of the hydrologic concerns related to wetlands in the United States. Can. J. Bot. 1986, 64, 364-374. [CrossRef]

4. Fisher, J.; Acreman, M. Wetland nutrient removal: A review of the evidence. Hydrol. Earth Syst. Sci. Discus. 2004, 8, 673-685. [CrossRef]

5. Hey, D.L.; Kostel, J.A.; Crumpton, W.G.; Mitsch, W.J.; Scott, B. The roles and benefits of wetlands in managing reactive nitrogen. J. Soil Water Conserv. 2012, 67, 47A-53A. [CrossRef]

6. Kingsford, R.T.; Basset, A.; Jackson, L. Wetlands: conservation's poor cousins. Aquat. Conserv. Mar. Freshw. Ecosyst. 2016, 26, 892-916. [CrossRef]

7. Amani, M.; Salehi, B.; Mahdavi, S.; Granger, J.; Brisco, B. Wetland classification in Newfoundland and Labrador using multi-source SAR and optical data integration. GISci. Remote Sens. 2017, 54, 779-796. [CrossRef]

8. Secretariat, R.C. Ramsar Handbooks for the Wise Use of Wetlands; Ramsar Convention Secretariat: Gland, Switzerland, 2007.

9. Ozesmi, S.L.; Bauer, M.E. Satellite remote sensing of wetlands. Wetl. Ecol. Manag. 2002, 10, $381-402$. [CrossRef]

10. Wulder, M.; Li, Z.; Campbell, E.; White, J.; Hobart, G.; Hermosilla, T.; Coops, N. A National Assessment of Wetland Status and Trends for Canada's Forested Ecosystems Using 33 Years of Earth Observation Satellite Data. Remote Sens. 2018, 10, 1623. [CrossRef]

11. Mahdavi, S.; Salehi, B.; Amani, M.; Granger, J.E.; Brisco, B.; Huang, W.; Hanson, A. Object-based classification of wetlands in Newfoundland and Labrador using multi-temporal PolSAR data. Can. J. Remote Sens. 2017, 43, 432-450. [CrossRef]

12. Amani, M.; Salehi, B.; Mahdavi, S.; Granger, J.E.; Brisco, B.; Hanson, A. Wetland classification using multi-source and multi-temporal optical remote sensing data in Newfoundland and Labrador, Canada. Can. J. Remote Sens. 2017, 43, 360-373. [CrossRef]

13. Montgomery, J.; Brisco, B.; Chasmer, L.; Devito, K.; Cobbaert, D.; Hopkinson, C. SAR and Lidar Temporal Data Fusion Approaches to Boreal Wetland Ecosystem Monitoring. Remote Sens. 2019, 11, 161. [CrossRef]

14. DeLancey, E.R.; Kariyeva, J.; Cranston, J.; Brisco, B. Monitoring hydro temporal variability in Alberta, Canada with multi-temporal Sentinel-1 SAR data. Can. J. Remote Sens. 2018, 44, 1-10. [CrossRef]

15. Fournier, R.A.; Grenier, M.; Lavoie, A.; Hélie, R. Towards a strategy to implement the Canadian Wetland Inventory using satellite remote sensing. Can. J. Remote Sens. 2007, 33, S1-S16. [CrossRef]

16. National Wetlands Working Group. The Canadian Wetland Classification System, 2nd ed.; Warner, B.G., Rubec, C.D.A., Eds.; National Wetlands Working Group, Wetlands Research Branch, University of Waterloo: Waterloo, ON, Canada, 1997.

17. White, L.; Millard, K.; Banks, S.; Richardson, M.; Pasher, J.; Duffe, J. Moving to the RADARSAT constellation mission: Comparing synthesized compact polarimetry and dual polarimetry data with fully polarimetric RADARSAT-2 data for image classification of peatlands. Remote Sens. 2017, 9, 573. [CrossRef]

18. Brisco, B.; Ahern, F.; Murnaghan, K.; White, L.; Canisus, F.; Lancaster, P. Seasonal change in wetland coherence as an aid to wetland monitoring. Remote Sens. 2017, 9, 158. [CrossRef] 
19. Ahern, F.; Brisco, B.; Murnaghan, K.; Lancaster, P.; Atwood, D.K. Insights Into Polarimetric Processing for Wetlands From Backscatter Modeling and Multi-Incidence Radarsat-2 Data. IEEE J. Sel. Top. Appl. Earth Obs. Remote Sens. 2018, 11, 3040-3050. [CrossRef]

20. Amani, M.; Salehi, B.; Mahdavi, S.; Brisco, B.; Shehata, M. A Multiple Classifier System to improve mapping complex land covers: A case study of wetland classification using SAR data in Newfoundland, Canada. Int. J. Remote Sens. 2018, 39, 7370-7383. [CrossRef]

21. Gorelick, N.; Hancher, M.; Dixon, M.; Ilyushchenko, S.; Thau, D.; Moore, R. Google Earth Engine: Planetary-scale geospatial analysis for everyone. Remote Sens. Environ. 2017, 202, 18-27. [CrossRef]

22. Kumar, L.; Mutanga, O. Google Earth Engine Applications Since Inception: Usage, Trends, and Potential. Remote Sens. 2018, 10, 1509. [CrossRef]

23. Dong, J.; Xiao, X.; Menarguez, M.A.; Zhang, G.; Qin, Y.; Thau, D.; Biradar, C.; Moore III, B. Mapping paddy rice planting area in northeastern Asia with Landsat 8 images, phenology-based algorithm and Google Earth Engine. Remote Sens. Environ. 2016, 185, 142-154. [CrossRef]

24. Chen, B.; Xiao, X.; Li, X.; Pan, L.; Doughty, R.; Ma, J.; Dong, J.; Qin, Y.; Zhao, B.; Wu, Z. A mangrove forest map of China in 2015: Analysis of time series Landsat 7/8 and Sentinel-1A imagery in Google Earth Engine cloud computing platform. ISPRS J. Photogramm. Remote Sens. 2017, 131, 104-120. [CrossRef]

25. Xiong, J.; Thenkabail, P.; Tilton, J.; Gumma, M.; Teluguntla, P.; Oliphant, A.; Congalton, R.; Yadav, K.; Gorelick, N. Nominal 30-m cropland extent map of continental Africa by integrating pixel-based and object-based algorithms using Sentinel-2 and Landsat-8 data on Google Earth Engine. Remote Sens. 2017, 9 , 1065. [CrossRef]

26. Environment and Climate Change Canada. Available online: https://www.canada.ca/en/environmentclimate-change/services/environmental-indicators/extent-wetlands.html (accessed on 15 February 2019).

27. Real Time Water Quality Monitoring Workshop (2018). Available online: https://www.mae.gov.nl.ca/ waterres/rti/rtwq/workshops.html\#2018 (accessed on 10 December 2018).

28. Environment and Climate Change Canada. Canadian Environmental Sustainability Indicators: Extent of Canada's Wetlands. Available online: www.ec.gc.ca/indicateurs-indicators/default.asp?lang=en\&n= 69E2D25B-1 (accessed on 15 February 2019).

29. Kottek, M.; Grieser, J.; Beck, C.; Rudolf, B.; Rubel, F. World map of the Köppen-Geiger climate classification updated. Meteorol. Z. 2006, 15, 259-263. [CrossRef]

30. Amani, M.; Salehi, B.; Mahdavi, S.; Brisco, B. Spectral analysis of wetlands using multi-source optical satellite imagery. ISPRS J. Photogramm. Remote Sens. 2018, 144, 119-136. [CrossRef]

31. Breiman, L. Random forests. Mach. Learn. 2001, 45, 5-32. [CrossRef]

32. Hermosilla, T.; Wulder, M.A.; White, J.C.; Coops, N.C.; Hobart, G.W. Disturbance-informed annual land cover classification maps of Canada's forested ecosystems for a 29-year Landsat time series. Can. J. Remote Sens. 2018, 44, 67-87. [CrossRef]

33. Hanna, M. Available online: https://sites.google.com/a/richland2.org/hanna-canada/urban-land-use (accessed on 15 May 2016).

34. Statistics Canada (2017). Available online: https://www150.statcan.gc.ca/n1/pub/95-640-x/2016001/ article/14816-eng.htm (accessed on 10 January 2019).

35. Natural Resources Canada. Available online: https://www.nrcan.gc.ca/forests/boreal/13071 (accessed on 15 January 2019).

36. Royal Canadian Geographical Society 2012. Available online: http://www.canadiangeographic.com/ youarehere/?path=english/nos_cartes-our_maps/marais-wetlands (accessed on 20 January 2019).

37. Smith, K.; Smith, C.; Forest, S.; Richard, A. A Field Guide to the Wetlands of the Boreal Plains Ecozone of Canada; Ducks Unlimited Canada, Western Boreal Office: Edmonton, AB, Canada, 2007.

38. Mitsch, W.J.; Gosselink, J.G. Wetlands, 3th ed.; Wiley: New York, NY, USA, 2000.

39. Adam, E.; Mutanga, O.; Rugege, D. Multispectral and hyperspectral remote sensing for identification and mapping of wetland vegetation: A review. Wetl. Ecol. Manag. 2010, 18, 281-296. [CrossRef]

40. McNairn, H.; Champagne, C.; Shang, J.; Holmstrom, D.; Reichert, G. Integration of optical and Synthetic Aperture Radar (SAR) imagery for delivering operational annual crop inventories. ISPRS J. Photogramm. Remote Sens. 2009, 64, 434-449. [CrossRef]

41. Zoltai, S.; Vitt, D. Canadian wetlands: Environmental gradients and classification. Vegetatio 1995, 118, 131-137. [CrossRef] 
42. Franklin, S.E.; Ahmed, O.S. Object-based Wetland Characterization Using Radarsat-2 Quad-Polarimetric SAR Data, Landsat-8 OLI Imagery, and Airborne Lidar-Derived Geomorphometric Variables. Photogramm. Eng. Remote Sens. 2017, 83, 27-36. [CrossRef]

43. Hird, J.; DeLancey, E.; McDermid, G.; Kariyeva, J. Google Earth Engine, open-access satellite data, and machine learning in support of large-area probabilistic wetland mapping. Remote Sens. 2017, 9, 1315. [CrossRef]

44. White, L.; Brisco, B.; Dabboor, M.; Schmitt, A.; Pratt, A. A collection of SAR methodologies for monitoring wetlands. Remote Sens. 2015, 7, 7615-7645. [CrossRef]

45. Powers, R.P.; Hay, G.J.; Chen, G. How wetland type and area differ through scale: A GEOBIA case study in Alberta's Boreal Plains. Remote Sens. Environ. 2012, 117, 135-145. [CrossRef]

46. Sustainable Forest Management in Canada. Available online: https://www.sfmcanada.org/en/canada-sforests (accessed on 10 February 2019).

47. Zheng, Y.; Niu, Z.; Gong, P.; Dai, Y.; Shangguan, W. Preliminary estimation of the organic carbon pool in China's wetlands. Chin. Sci. Bull. 2013, 58, 662-670. [CrossRef]

48. Paudel, R.; Mahowald, N.M.; Hess, P.G.; Meng, L.; Riley, W.J. Attribution of changes in global wetland methane emissions from pre-industrial to present using CLM4. 5-BGC. Environ. Res. Lett. 2016, 11, 034020. [CrossRef]

49. Lee, S.; Yeo, I.-Y.; Lang, M.; Sadeghi, A.; McCarty, G.; Moglen, G.; Evenson, G. Assessing the cumulative impacts of geographically isolated wetlands on watershed hydrology using the SWAT model coupled with improved wetland modules. J. Environ. Manag. 2018, 223, 37-48. [CrossRef] [PubMed]

50. Hanson, A.; Swanson, L.; Ewing, D.; Grabas, G.; Meyer, S.; Ross, L.; Watmough, M.; Kirkby, J. Wetland ecological functions assessment: An overview of approaches. Can. Wildl. Serv. Tech. Rep. Ser. 2008, 16, 123-125.

51. Dahl, T.E. Status and Trends of Wetlands in the Conterminous United States 2004 to 2009; US Department of the Interior: Washington, DC, USA; US Fish and Wildlife Service: Washington, DC, USA; Fisheries and Habitat Conservation: Silver Spring, MD, USA, 2011.

52. Sun, T.; Lin, W.; Chen, G.; Guo, P.; Zeng, Y. Wetland ecosystem health assessment through integrating remote sensing and inventory data with an assessment model for the Hangzhou Bay, China. Sci. Total Environ. 2016, 566, 627-640. [CrossRef]

53. U.S. EPA. National Wetland Condition Assessment 2016: Site Evaluation Guidelines; EPA-843-R-15-010; U.S. Environmental Protection Agency: Washington, DC, USA, 2016. 